\title{
Assessment of Possible Health Risks Potential of Electromagnetic Fields from High Voltage Power Transmission Lines in Akure, Nigeria
}

\author{
Jide Julius Popoola ${ }^{\mathrm{a},}{ }^{*}$, Michael Rotimi Adu ${ }^{\mathrm{a}}$ and Emmanuel Samson Itodo ${ }^{\mathrm{a}}$ \\ ${ }^{a}$ Electrical and Electronics Engineering Department, School of Engineering and Engineering, \\ Federal University of Technology, Akure, Ondo State, Nigeria
}

\begin{abstract}
The primary objective of this paper is to assess and predict the health risk potential of extremely lowfrequency electromagnetic fields (ELF-EMFs) emitted from high voltage power transmission lines (HVPTLs) in Akure metropolis, Nigeria. The assessment was conducted using BENETECH GM3120 Electromagnetic Radiation Tester to measure both the electric field strength and magnetic flux density emitted from $33 \mathrm{kV}, 132 \mathrm{kV}, 132 / 330 \mathrm{kV}$ and $330 \mathrm{kV}$ power transmission lines within the metropolis. The data collected were analysed and compared with limiting tolerable values by the International Commission on Non-Ionizing Radiation Protection (ICNIRP) guidelines for both occupational and the general public. The comparative result shows that the maximum measured electric field strength and magnetic flux density in this study are lower than $40 \%$ of the limiting tolerable values in ICNIRP guidelines. Thus, the result of this study has shown clearly that the emitted ELF-EMFs from HVPTLs is not strong enough to cause any adverse effect health on human. In addition, analysis of the measured data also shows that the emitted ELF-EMFs from the HVPTLs vanish completely at about $60 \mathrm{~m}$ radius from the transmission lines, which implies that $60 \mathrm{~m}$ radius from transmission lines is an ideal experimental shortest possible distance residential building and people should be from HVPTLs in order to reduce the exposure level of people to EMFs radiations from HVPTLs.
\end{abstract}

Keywords: Transmission Lines, Radiation, Electromagnetic Fields

\section{Introduction}

The three primary sections usually involve in delivering electricity to consumers either at residential or industrial areas are power generation plants, transmission facilities and distributions, also known as consumers. Among these three primary sections, transmission facilities are normally the bridge connecting the power produced at the generation stations and the consumers. The transmission facilities comprise transmission lines, which are high-voltage power lines extended from power generating plants to convey electric power efficiently over long distances. The bulk transportation of electricity across long distances is normally through either underground or overhead transmission lines. While underground high voltage transmission lines are used in transporting power through underwater and densely populated urban and suburban areas where there is no sufficient rightof-way (RoW), the overhead high voltage transmission lines can be used in both sparsely and densely populated areas in urban, suburban and rural environments once there is sufficient RoW.

Thus, in both developed and underdeveloped nations of the world, usage of underground transmission lines for power or electricity are less common than overhead transmission lines due to

\footnotetext{
* Corresponding author. Tel.: +234-803-413-1860

E-mail address: jidejulius2001@gmail.com

Manuscript History:

Received 12 February, 2021, Revised 18 April, 2021, Accepted 19 April, 2021, Published 30 April, 2021
}

e-ISSN: $2289-7771$

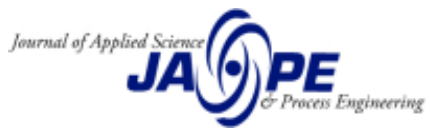


heat related losses, long power-restoration duration and higher cost [1,2]. However, as reported in [3], usage of overhead high voltage transmission lines in transmitting electricity is not without its disadvantage as a result of the large areas and distances it covers and other negative impacts it produces. One of the disadvantages of overhead high voltage transmission lines is that the electric and magnetic fields generated by overhead transmission lines during power transmission have been identified as a major cause of diverse health risks and safety [4-9], environmental risks [10] and biological effects [8] in the society.

However, as a result of the present technological development worldwide, transmission and usage of electricity are currently increasing on daily basis over the last few decades. Similarly, the construction and extension of power transmission lines have become one of the prominent contracts across the globe. This is because electricity has become an indispensable part of today's society. For instance, as reported in [11], observations have shown that better health systems and sustainable health development goals cannot be achieved without electricity. In fact, according to [12], electricity has become a critical universal enabler to health care services, which its unavailability will surely make many life-saving health interventions inaccessible. Furthermore, it has equally been established that improving access to electricity with reliable supply and voltage stability will positively have positive impacts on health [13-15]. Due to this benefit and many others in society, transmission and usage of electricity have increased greatly in recent times.

However, it has been observed that whenever electricity is generated, transmitted and/or consumed, electromagnet fields (EMFs) are always generated. Thus, profuse usage of HVPTLs has invariably led to the availability of EMFs exposure from HVPTLs and high criticism as a result of EMFs adverse effect on human health. Therefore as a result of its negative health effect, the construction of new overhead HVPTLs, as reported in [16], has been considerably opposed in some nations of the world. This has led to unique concern on the relationship between the occurrence of some diseases or illnesses and EMFs radiated from HVPTLs. For instance, [17] reported the health risks associated with people living in proximity to HVPTLs. Specifically, the possibility of childhood cancer and exposure to EMFs from HVPTLs has been a research interest for the past three decades. Findings reported in [18] revealed that 20 per cent of the total population of people in Tehra, the capital of Iran living near HVPTLs died of leukaemia as a result of exposure to ELF-EMFs. In addition, findings from two different studies from France and the United States (US), reported in [19] revealed that people living within 50 meters of over $200 \mathrm{kV}$ power lines may become victims of childhood leukaemia in the two nations. Similarly, the result of the study conducted in the United Kingdom (UK) by [20] shows a perfect connection between childhood leukaemia and distance between home address at birth and proximity to high voltage overhead power line with risk extending out to about 600 meters. Similarly, Reference [21] also found an increased risk of adult brain tumours among residents living very close to high power lines. Furthermore, as reported in [22] charged corona ions formed in the neighbourhood of power lines when interacting with an airborne particle can lead to harmful health effect.

With the current global economic development, electricity demand and usage is increasing on daily basis. This is evidence in the world annual electricity consumption that rose from $7300 \mathrm{TWh}$ to 22,100 TWh between 1980 and 2013. The per capita electricity demand projection in Nigeria equally shows a progressive annual increase from $1106 \mathrm{kWh}$ per capita in 2015 to $5002 \mathrm{kWh}$ per capita in 2030 [23]. This progressive increase in usage and demand for electricity shows the possibility of corresponding progress in EMFs in society. This is stemmed from the fact that whenever electricity is generated, transmitted and/or consumed, EMFs are always generated. This ubiquitous of EMFs in our environment has indeed increased daily exposure to EMFs and their hazardous effects on the general public due to some hazardous effects associated with EMFs radiation.

Radiation is energy that emitted from a source and travels through space with the potential to penetrate various materials. Thus, living organisms (man, animals and plants) are profoundly affected by radiation. For instance, in human beings, radiation causes diverse responses, which are determined by series of parameters including radiation dosage or amount of radiation energy received, radiation 
source, the genetic and epigenetic constituents of the exposed individual as well as the length of exposure. Generally, radiation is classified into two major classes: ionizing radiation (IR) and nonionizing (NIR). Although EMFs associated with electricity and/or HVPTLs is a typical low-frequency NIR, its ability to harm biological tissues had been successively established in [24]. However, none of the surveyed literature specifically mentioned the permissive shortest distance residential accommodation or buildings and people should be to HVPTLs concerning various power lines voltage ranges. For instance, in [25], it was established that for every more than 600 meters away from 123 $\mathrm{kV}, 230 \mathrm{kV}$ and $400 \mathrm{kV}$ respectively in Iran, there is a reduction in the risk of childhood acute lymphoblastic leukaemia. Thus, in the study presented in this paper, the variation of electric field (EF) and magnetic field (MF) that constitute EMFs with distance will be studied to ascertain possible shortest distance residential building and people can be from HVPTLs especially in Nigeria where people do not only build very close to HVPTLs, as shown in Figure 1(a) but equally constructed workshops directly under HVPTLs as shown in Figure 1(b). In achieving the goal, measurements of electric field strength, magnetic field strength and magnetic flux density around various voltage range HVPTLs were conducted. Detailed information on the measurements carried out is presented in section 3 of the paper while a brief review on EMFs and their inherent health risk potential is presented in section 2. The results of the analysis conducted on data obtained in section 3 are presented and discussed in section 4 . The paper is finally concluded in section 5 with a summary of the findings of the study.

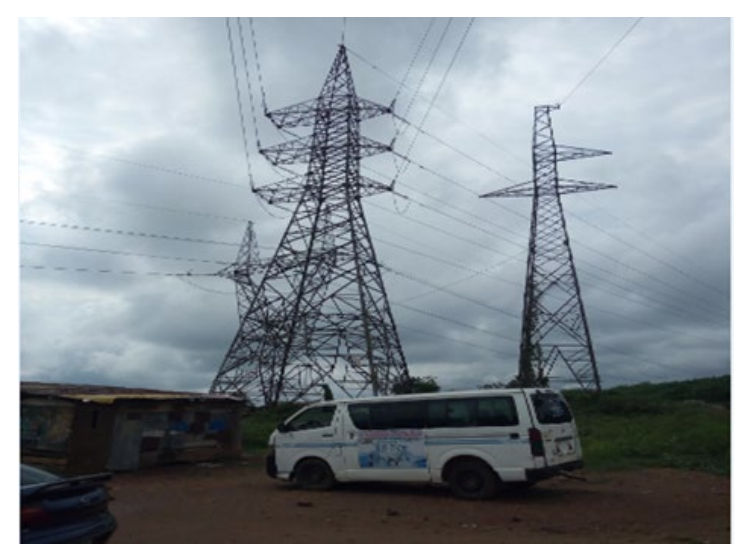

(a)

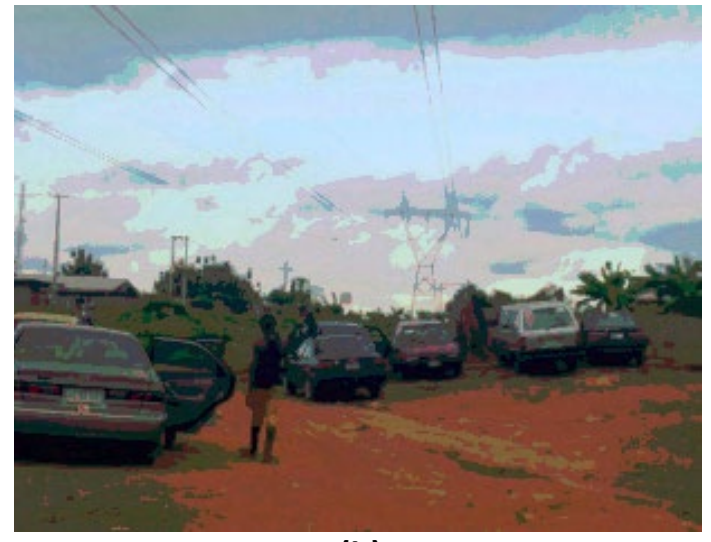

(b)

Figure 1. (a) Typical residential building beside and (b) Artisans workshops under HVPTLs in Akure metropolis, Nigeria.

\section{Brief review on EMFs and their inherent health risks}

EMFs refer to time-varying vector quantities that depend on their frequency, phase angle, magnitude and direction. It comprises two different but related concepts namely; an electric field and a magnetic field. The electric and magnetic fields at a frequency range from $0-300 \mathrm{~Hz}$ are sometimes produced either naturally or as a result of human activities. All alternating currents generate EMFs [26]. While the magnetic field (MF) is proportional to the current, which is the amount of electricity flowing through the wire, the electric field $(\mathrm{EF})$ is proportional to the voltage. MF is generally specified using either magnetic flux density, B, measured in Tesla (T) or magnetic field strength, $\mathrm{H}$, measured in Ampere per meter $\left(A \mathrm{~m}^{-1}\right)$. The two quantities according to [27] are related mathematically as; 


$$
B=\mu H
$$

where $\mu$ is magnetic permeability in a vacuum and air as well as non-magnetic materials such as human tissues. Similarly, according to [27], the internal electric field, $E_{i}$, and current density, $J$, are related mathematically as;

$$
J=\sigma H
$$

where $\sigma$ is the electrical conductivity of the medium. As reported in [17], the current density, $J$, from Ohm's laws depends on the magnetic flux density and field frequency, $f$, derived from Faraday's law of induction and radius, $R$, of the induction loop and is expressed mathematically as;

$$
J=\pi R f B
$$

From (3), it is obvious that $B$ decreases approximately in a linear fashion with distance from the current-carrying conductor. Hence, MF will induce a subtle electric current within the body at a shorter distance than at a longer distance from the emitting source. The resulted in induced current in the body is not conducted to the ground but causes high voltage difference within the body. The interaction of these time-varying low EF and MF with the human body consequently result in the flowing of electric charges, reorientation of electric dipoles already present in human tissue and polarization of bound charge. According to [28], the relative magnitudes of different effects the interaction of time-varying low EF and MF cause depend on both the magnetic permittivity $(\mu)$ and electrical conductivity $(\sigma)$ in equations (1) and (2) respectively. According to [28], it was observed that exposure to low-frequency EF and MF do not cause significant energy absorption as well as a measurable increase in the body temperature. However, their homogeneous exposures do lead to the high inhomogeneous distribution of energy within the body, which does result in some possible health effects and can be determined by both dosimetric measurements and calculations.

Therefore, different bodies both at national and international levels have provided different guidelines for determining the limiting exposure level of EMFs in the human body. The main objective of the guidelines is to protect against adverse health effect associated with time-varying electric and magnetic fields. The guidelines were published for safe occupational and general exposure to power-frequency electric and magnetic fields. For instance, the International Commission on Non-ionizing Radiation Protection (ICNIRP) has published guidelines for limiting exposure to time-varying electric and magnetic fields in the range of $1 \mathrm{~Hz}$ to $100 \mathrm{kHz}$ [27]. According to the guidelines, as reported in [29], the reference levels for $50 \mathrm{~Hz}$ time-varying electric and magnetic fields for general public exposure are $5 \mathrm{kV} / \mathrm{m}$ and $200 \mu \mathrm{T}$ while the corresponding values for occupational exposure for $50 \mathrm{~Hz}$ are $10 \mathrm{kV} / \mathrm{m}$ and $1000 \mu \mathrm{T}$ respectively. Similarly, the Directive 2004/40/EU published on April 30, 2004, in the European Union provides limit exposure occupational values of 10 $\mathrm{kV} / \mathrm{m}$ electric field and $500 \mu \mathrm{T}$ magnetic flux density and an action value of $50 \mathrm{~Hz}$ at total contact current of $1 \mathrm{~mA}$ [30]. Comprehensive unperturbed root means square (RMS) limiting reference ICNIRP Guidelines values for both occupational and general public exposure to time-varying electric and magnetic fields in [27] are presented in Table 1 and Table 2 respectively. 
Table 1. Occupancy reference levels for time-varying electric and magnetic fields (Source: ICNIRP, 2010)

\begin{tabular}{|c|c|c|c|}
\hline $\begin{array}{c}\text { Frequency } \\
\text { Range }\end{array}$ & $\begin{array}{c}\text { Electric Field } \\
\text { Strength, E } \\
(\mathbf{k V} / \mathbf{m})\end{array}$ & $\begin{array}{c}\text { Magnetic Field } \\
\text { Strength, H } \\
(\mathbf{A} / \mathbf{m})\end{array}$ & $\begin{array}{c}\text { Electric Field } \\
\text { Strength, B } \\
\mathbf{( T )}\end{array}$ \\
\hline $1 \mathrm{~Hz}-8 \mathrm{~Hz}$ & 20 & $1.63 \times 10^{5} / f^{2}$ & $0.2 / f$ \\
\hline $8 \mathrm{~Hz}-25 \mathrm{~Hz}$ & 20 & $2.0 \times 10^{4} / f$ & $2.5 \times 10^{-2} / f$ \\
\hline $25 \mathrm{~Hz}-300 \mathrm{~Hz}$ & $5.0 \times 10^{2} / f$ & $8.0 \times 10^{2}$ & $1.0 \times 10^{-3}$ \\
\hline $5300 \mathrm{~Hz}-3 \mathrm{kHz}$ & $5.0 \times 10^{2} / f$ & $2.4 \times 10^{5} / f$ & $0.3 / f$ \\
\hline $3 \mathrm{kHz}-10 \mathrm{MHz}$ & $1.7 \times 10^{-2}$ & 80 & $1.0 \times 10^{-4}$ \\
\hline
\end{tabular}

where $f$ is the frequency indicated in the frequency range column.

Table 2. General public reference levels for time-varying electric and magnetic fields (Source:

ICNIRP, 2010)

\begin{tabular}{|c|c|c|c|}
\hline $\begin{array}{c}\text { Frequency } \\
\text { Range }\end{array}$ & $\begin{array}{c}\text { Electric Field } \\
\text { Strength, E } \\
(\mathbf{k V} / \mathbf{m})\end{array}$ & $\begin{array}{c}\text { Magnetic Field } \\
\text { Strength, H } \\
(\mathbf{A} / \mathbf{m})\end{array}$ & $\begin{array}{c}\text { Electric Field } \\
\text { Strength, B } \\
\text { (T) }\end{array}$ \\
\hline $1 \mathrm{~Hz}-8 \mathrm{~Hz}$ & 5 & $3.2 \times 10^{4} / f^{2}$ & $4.0 \times 10^{-2} / f^{2}$ \\
\hline $8 \mathrm{~Hz}-25 \mathrm{~Hz}$ & 5 & $4.0 \times 10^{3} / f$ & $5.0 \times 10^{-3} / f^{2}$ \\
\hline $25 \mathrm{~Hz}-50 \mathrm{~Hz}$ & 5 & $1.6 \times 10^{2}$ & $2.0 \times 10^{-4}$ \\
\hline $50 \mathrm{~Hz}-400 \mathrm{~Hz}$ & $2.5 \times 10^{2} / f$ & $1.6 \times 10^{2}$ & $2.0 \times 10^{-4}$ \\
\hline $400 \mathrm{~Hz}-3 \mathrm{kHz}$ & $2.5 \times 10^{2} / f$ & $6.4 \times 10^{4} / f$ & $8.0 \times 10^{-2} / f$ \\
\hline $3 \mathrm{kHz}-10 \mathrm{MHz}$ & $8.3 \times 10^{-2}$ & 21 & $2.7 \times 10^{-5}$ \\
\hline
\end{tabular}

where $f$ is the frequency indicated in the frequency range column.

Thus, according to [28], it is obvious that measurement of both time-varying electric and magnetic fields emitted by a radioactive source can indeed be used in assessing or determining the actual value of the radiation in the human body. The approach was therefore employed in the study presented in this paper. The novelty of the study presented in this paper is on its application of only measured EMFs radiation data to predict the possible health risk potential of emitted ELF-EMFs from HVPTLs without using the popular dosimetric measurements and calculations employed in most previous studies in surveyed literature. In addition, the study has established an experimental possible shortest distance residential building and people can be from HVPTLs to reduce the exposure level of people to EMFs radiations from HVPTLs. In achieving these contributions to knowledge, timevarying electric and magnetic fields emitted from $330 \mathrm{kV}$ for the grid transmission lines, $132 \mathrm{kV}$ for the sub-transmission lines as well as $33 \mathrm{kV}$ for low transmission lines were measured. Detailed information on how the measurements were conducted is presented in the next section under the materials and method.

\section{Materials and Method}

This section is divided into two parts based on activities involved in carrying out the study reported in this paper. The first part presents detailed information on the study site and the reasons for its choice. The second part provides a detailed description of the measuring tools employed in carrying out the study. In addition, the second part equally provides information on how the measured data were collected. Detailed information on the two parts is presented in the following subsections. 


\subsection{Study site description}

The data employed for this study were collected in Akure, the capital of Ondo State, Nigeria as well as the headquarters of Akure South Local Government Area. The metropolis is situated on latitude $7.250^{\circ} \mathrm{N}$ and longitude $5.195^{\circ} \mathrm{E}$. The choice of the metropolis as the data collection site was based on these two facts: one, because Akure is the most populated metropolis in Ondo State [31], which implies that the majority of people living and working in the metropolis can be under EMF hazardous effect without knowing; and two, because of the availability of the four categories of the overhead HVPTLs considered in the metropolis. In addition, Akure was used as the study site because Thus, the study

\subsection{Measuring tools description and data collection}

The two simple measuring tools employed in carrying out the field measurements conducted are shown in Figure 2(a) and Figure 2(b). While the BENETECH GM3120 Electromagnetic Radiation Tester shown in Figure 2(a) was employed in measuring the EMFs emitted around the $33 \mathrm{kV}, 132 \mathrm{kV}$, $330 \mathrm{kV}$ and 330/132 kV power transmission lines, the measuring tape, shown in Figure 2(b), was used to measure the distance of the residential buildings and the artisan's workshops from the power transmission lines in the vicinities. The meter was kept at about 1.5 meters above the ground facing the transmission lines and held steady during the measurement to enhance the accuracy of the measured fields. The measured were conducted nine (9) hours daily (7:00 am to 12:00 noon and 4:00 pm to 8:00 pm) for a period of three weeks. At each location, measurements were conducted in increasing interval of 5 meters to 100 meters from the centre of the base of each power transmission line. The measurements at each time and location were recorded when the reading was stabilized. The BENETECH GM3120 Electromagnetic Radiation Tester was used because of its inherent capability of detecting unperturbed RMS low-frequency EMFs from $5 \mathrm{~Hz}$ to $3500 \mathrm{~Hz}$. The meter measures the EMFs strength and displays the results in digit form. It also displays the measured quantities in two modes, namely the peak to peak value and absolute value. Thus, the peak to peak electric field strength and magnetic flux density values were measured and were represented respectively as $E_{p p}$ and $B_{p p}$. Similarly, the respective measured absolute electric field strength and magnetic flux density values were represented respectively as $E_{a b}$ and $B_{a b}$. The voltage levels considered at different locations within the metropolis where the emitted EMFs radiation was measured are presented in Table 3 . The measured electric field strength and magnetic flux density values against distance towards and away from the transmission lines were presented graphically in section 4 under the results and discussion. 

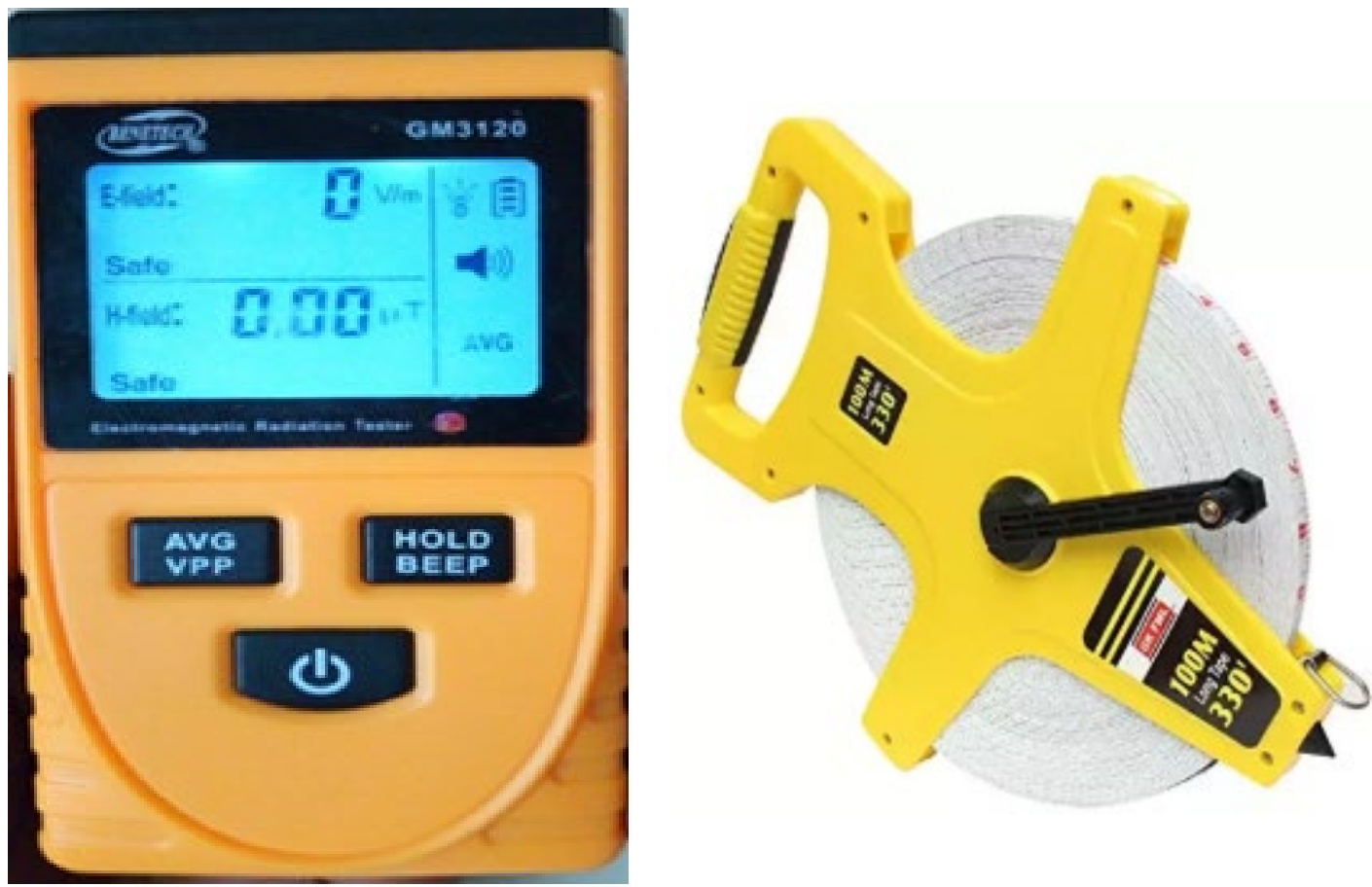

Figure 2. (a). BENETECH GM3120 electromagnetic radiation tester and (b) 100-meter measuring tape

Table 3. Voltage levels considered and locations

\begin{tabular}{|c|c|}
\hline $\begin{array}{l}\text { Voltage } \\
\text { level }(\mathbf{k V})\end{array}$ & Location \\
\hline 33 & $\begin{array}{c}\text { WESCO, FUTA Great Hall South Campus, RCF Area FUTA } \\
\text { South Gate and AKAD Area }\end{array}$ \\
\hline 132 & $\begin{array}{l}\text { Iralepo, Champion Junction, Agagu Road and Champion } \\
\text { Substation }\end{array}$ \\
\hline $132 / 330$ & AKAD \\
\hline 330 & Isinkan Road, Oludugbo Area, Adelabu Area and Agagu Road \\
\hline
\end{tabular}

\section{Results and Discussion}

The measured peak to peak electric field strength, $E_{p p}$, and measured peak to peak magnetic flux density, $B_{p p}$, as well as obtained measured absolute values for the electric field strength, $E_{a b}$, and magnetic flux density, $B_{a b}$, were plotted against distance. The corresponding magnetic field strength, $H_{p p}$, and $H_{a b}$ were calculated using equation (2). The graphical results obtained are presented and discussed in this section. The results and discussion presented in this section are divided into two subsections. In the first subsection, the graphical results obtained were first validated by comparing them with the standard result and similar result in a related study in surveyed literature. In the second subsection, the results of the analyzed measured data were compared with ICNIRP guidelines presented in Table 1 and Table 2 for occupational and general public respectively to infer whether the emitted radiation from the ELF-EMFs investigated in this study can cause health risk or not. Due to limited space, one electric field strength, magnetic field strength and magnetic flux density graphical result for each voltage level were presented. The obtained graphical results of the measured 
electric field strength against distance were presented in Figures 4(a) - (d) while the corresponding obtained graphical results of the calculated magnetic field strength against distance were presented in Figures 5(a) - (d). Figures 6(a) - (d) similarly show the obtained plots of the measured magnetic flux density obtained against distance. Detailed on each of the two subsections is presented as follows in the following two subsections.

\subsection{Measured data validation}

The validation of the measured data was first conducted to ascertain the correctness and reliability of the measured EMFs' variables for the study. The measured electric field strength and the corresponding magnetic flux density, as well as the magnetic field strength, were transformed into graphs. This was done to allow easy comparison of the obtained graphical results' shapes for this study with the standard shape of the expected result provided in the ICNIRP guideline. The standard or expected shape, according to Reference [27], shown in Figure 3, was retrieved from [32]. The obtained graphical results for the measured electric field strength against distance and the corresponding magnetic flux density as well as the magnetic field strength for this study are shown in Figures 4-6 respectively.

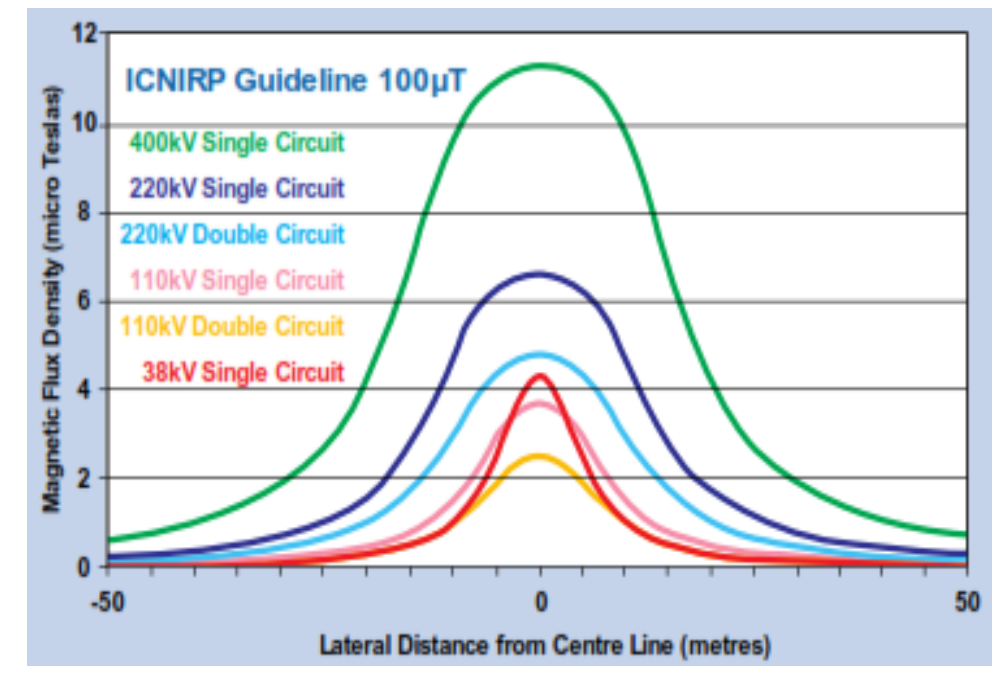

Figure 3. Standard expected shape of magnetic flux density against distance [27] 

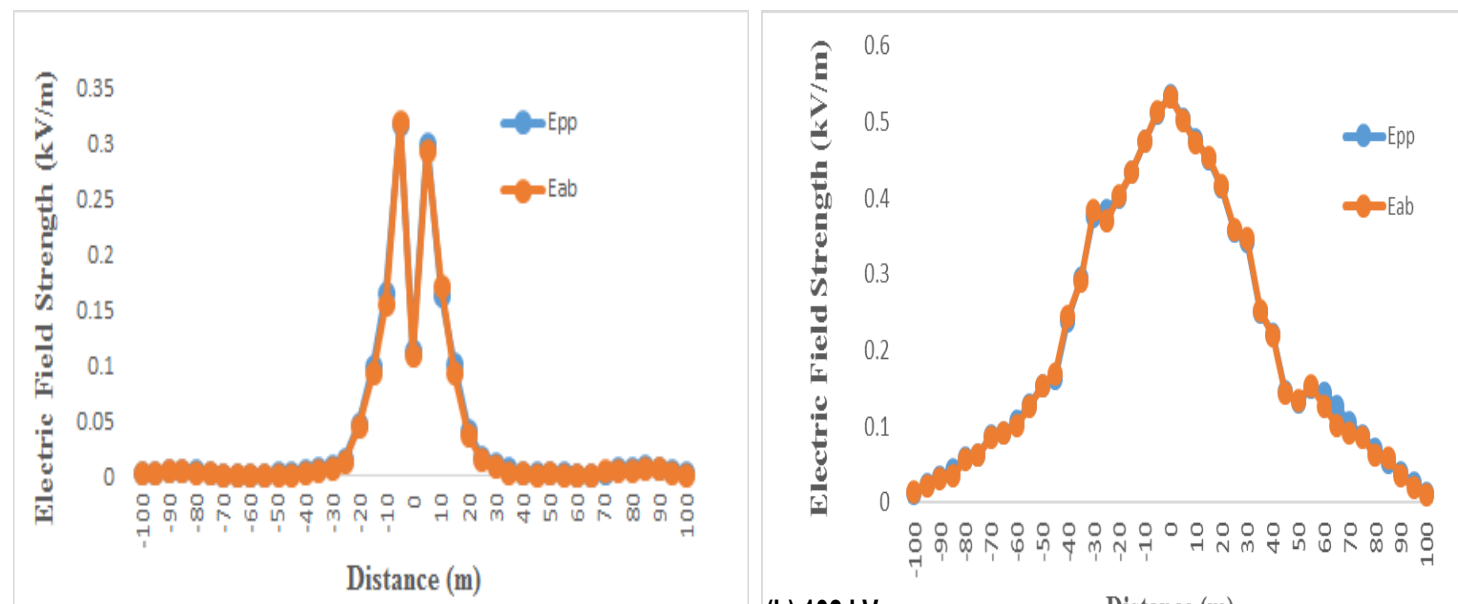

(a) $33 \mathrm{kV}$

(b) $132 \mathrm{kV} \quad$ Distance (m)
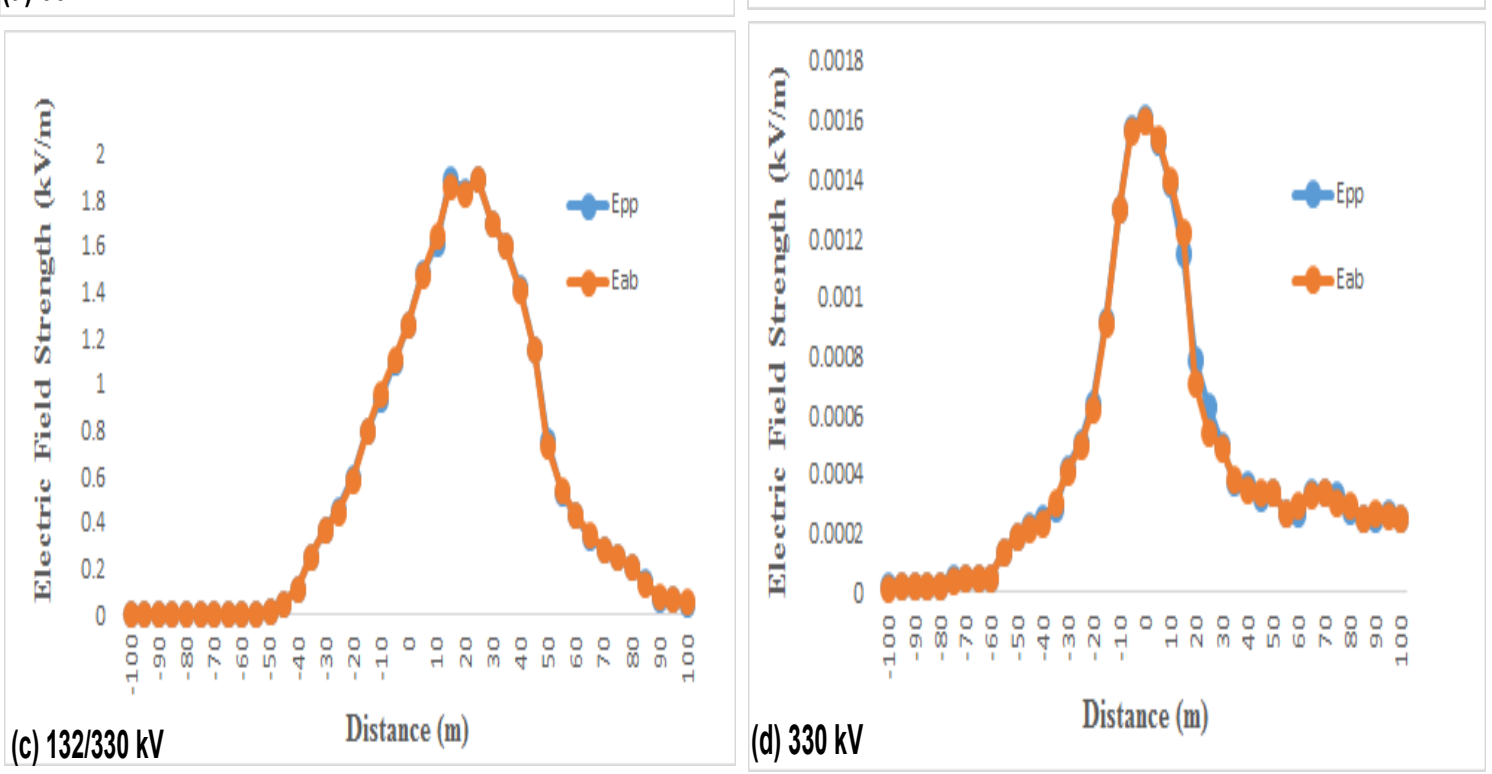

Figure 4. Plots of measured electric field strength against distance for (a) $33 \mathrm{kV}$, (b) $132 \mathrm{kV}$, (c) $132 / 330 \mathrm{kV}$ and (d) $330 \mathrm{kV}$ respectively 


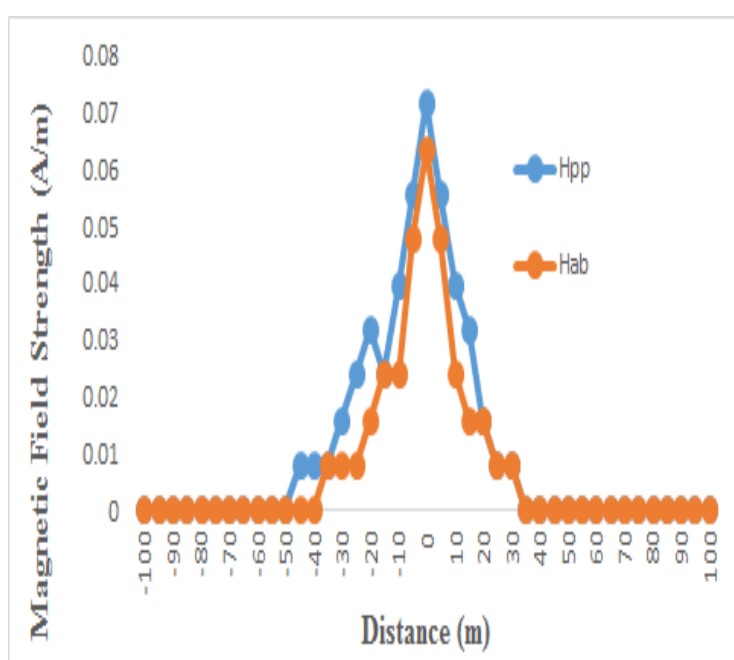

(a) $33 \mathrm{kV}$

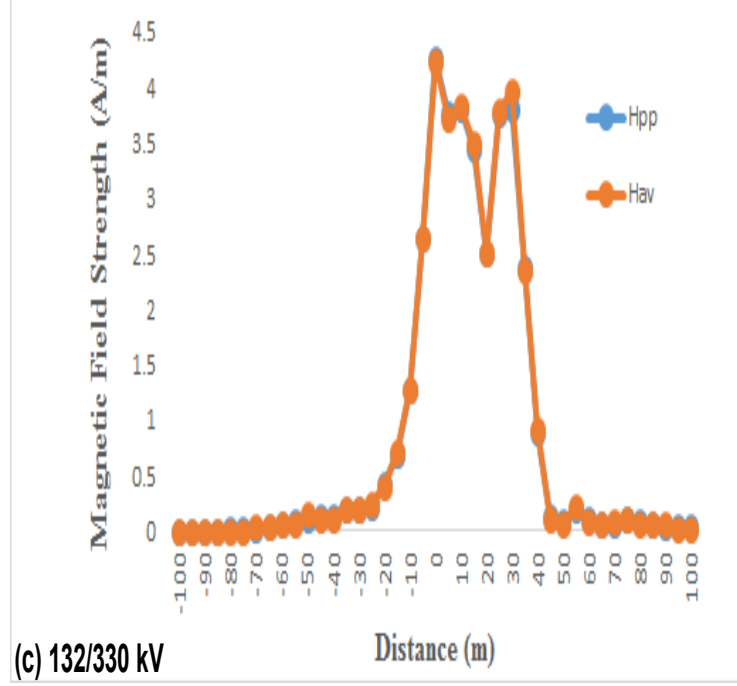

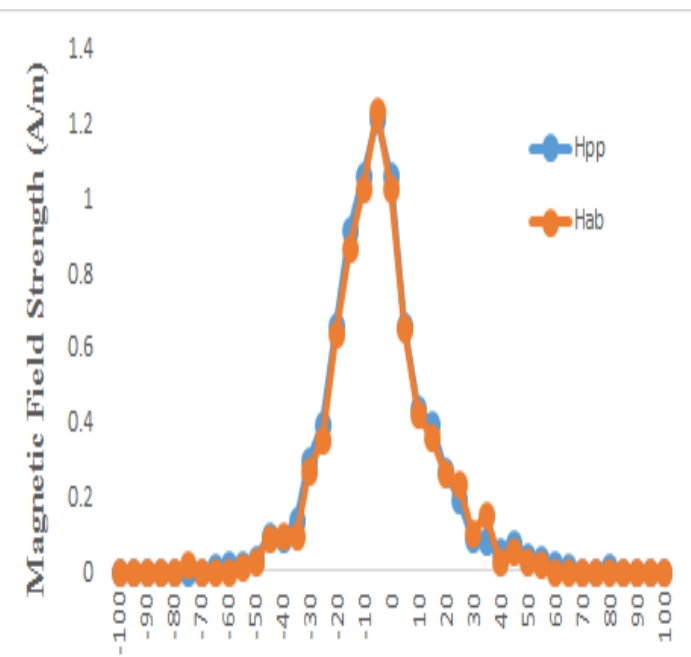

(b) $132 \mathrm{kV}$

Distance (m)

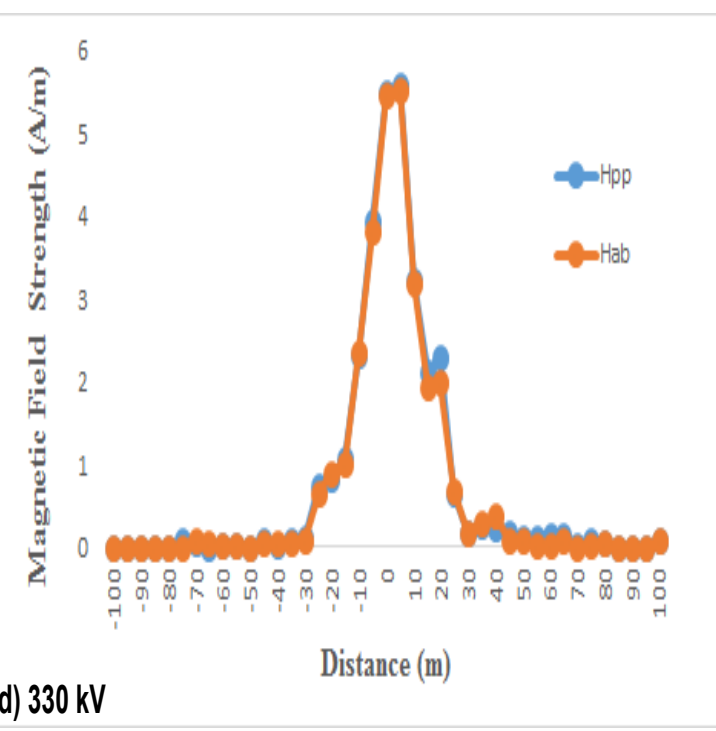

Figure 5. Plots of measured magnetic field strength against distance for (a) $33 \mathrm{kV}$, (b) $132 \mathrm{kV}$, (c) $132 / 330 \mathrm{kV}$ and (d) $330 \mathrm{kV}$ respectively 


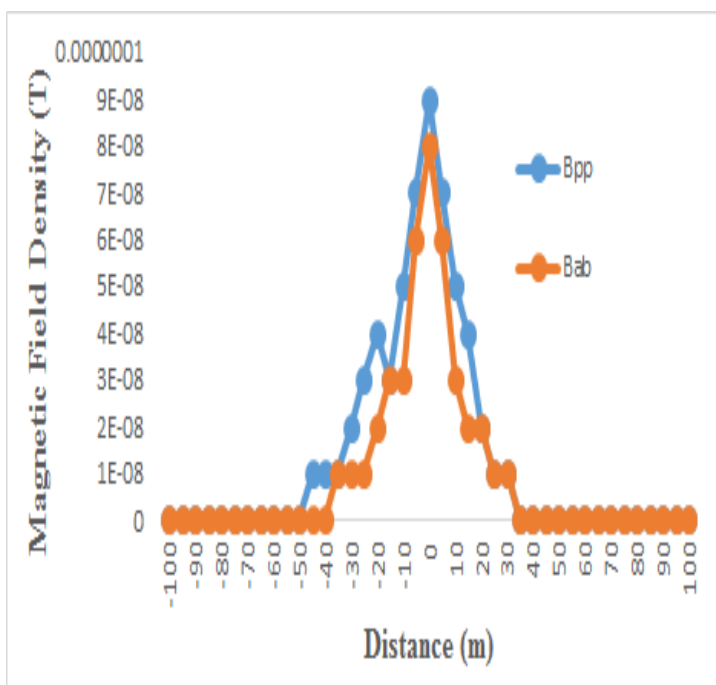

(a) $33 \mathrm{kV}$

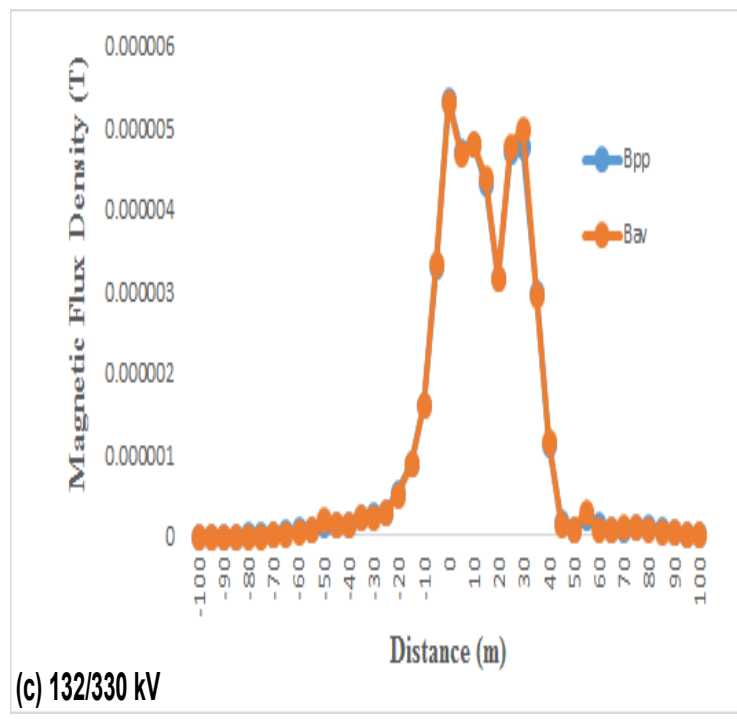

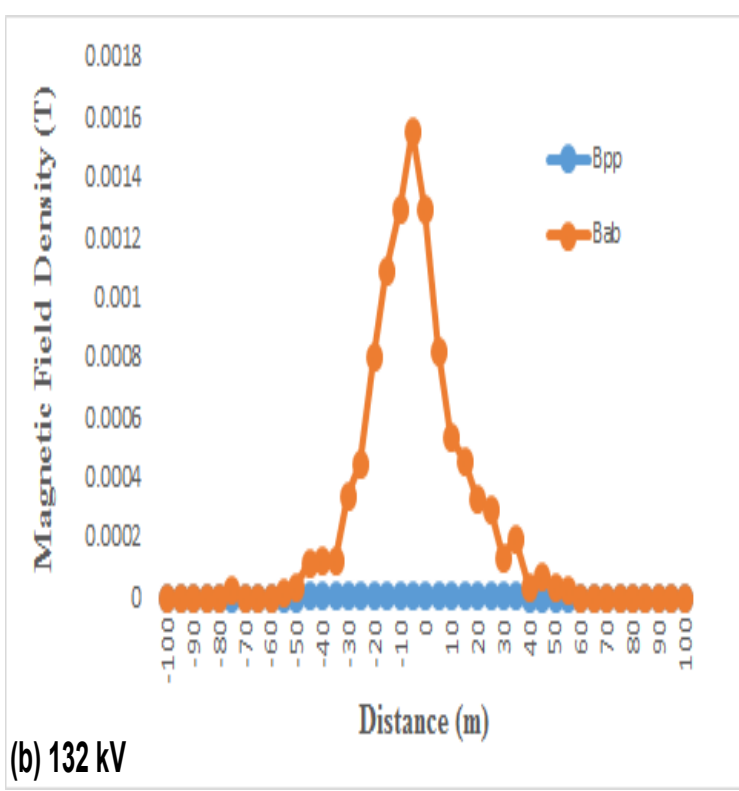

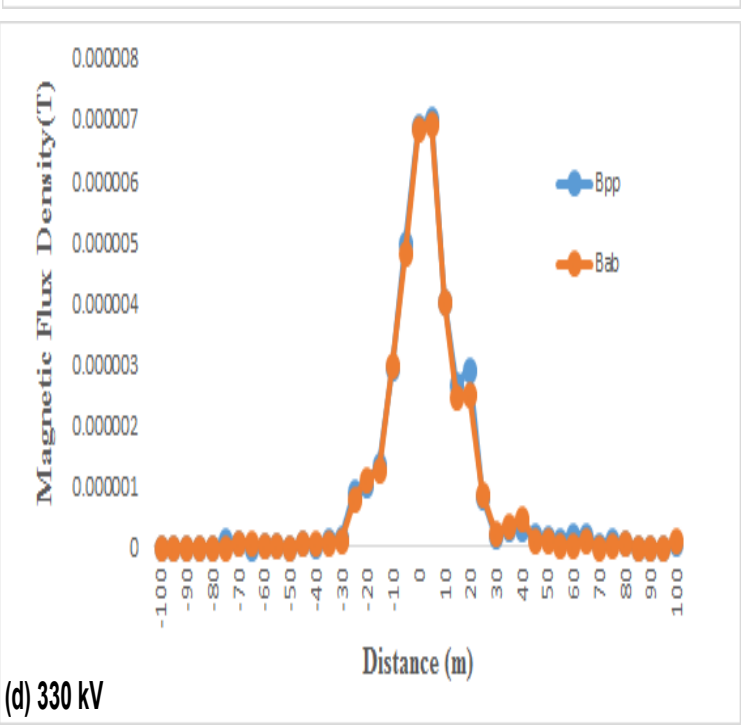

Figure 6. Plots of measured magnetic flux density against distance for (a) $33 \mathrm{kV}$, (b) $132 \mathrm{kV}$, (c) $132 / 330 \mathrm{kV}$ and (d) $330 \mathrm{kV}$ respectively

Critical comparative observations of Figure 3 and Figures 4-6 show clearly that the shapes of the obtained graphs from the measured data for this study presented in Figures 4, 5 and 6 resemble the shape of the expected or standard graph shown in Figure 3. Although exact perfect visual resemblance was not obtained, due to the variation in the voltage levels considered. However, the measured data obtained equally vanish at different distances from the power transmission lines depending on the voltage level as observed in the standard graph shown in Figure 3. This implies that the measured data for this study are not only accurate but are equally reliable as well as in conformity with the standard or expected behavioural nature. In addition, the result of the comparative analysis conducted equally shows that the measurements conducted were not only perfectly conducted but were accurately read and recorded. 
In addition, the measured data presented graphically in Figures 4-6, show that the values of the electric field strength, magnetic field strength and the magnetic flux density radiated decrease with an increase in distance in both directions as observed in the reference graph shown in Figure 3. Furthermore, the measured values for the two fields are found to be relatively close for both measurements made toward and away from the centre of the transmission lines. This implies that radiated fields in electric and magnetic forms from the four voltage levels are uniformly radiated in both directions as observed in Figure 3. This indicates that the health risks potential if any, the fields can cause will be uniform with respect to distance either away from or toward the transmission lines till about $60 \mathrm{~m}$ where the effect of the fields vanishes away in Figures 4-6.

Similarly, critical observations of Figures 4(a) - (d), Figures 5(a) - (d) and Figures 6(a) - (d) show that the higher the voltage level of the transmission lines the higher the distance its effect cover. For instances, while the electric field strength emitted from $33 \mathrm{kV}$ in Figure 4(a) vanishes at approximately $25 \mathrm{~m}$, the electric field strength emitted from $330 \mathrm{kV}$ in Figure 4(d) vanishes at approximately $60 \mathrm{~m}$. On the other, the results obtained show that irrespective of the voltage level, the effect of the emitted magnetic field strength vanishes at approximately at the same level. For example, while the magnetic field strength emitted from $132 \mathrm{kV}$ in Figure 5(b) vanishes at approximately $35 \mathrm{~m}$, the magnetic field strength emitted from $132 / 330 \mathrm{kV}$ in Figure 5(c) also vanishes at approximately 35 $\mathrm{m}$. This implies that the effects produced by both the electric field strength and the magnetic field strength vary with distance. Also, the result of this study shows at large that at about $60 \mathrm{~m}$ radius from the power transmission lines, both electric field strength and magnetic field strength generated or emitted vanished away completely.

This result has experimentally established the fact that $60 \mathrm{~m}$ radius from the power transmission lines can be taken as possible shortest distance residential building and people can be from HVPTLs in order to reduce the exposure level of people to EMFs radiations from HVPTLs. This observation is also in agreement with the finding in [7] that as the distance increases the ELF-EMFs exposure levels is usually decreased, which means that emitted ELF-EMFs strength is inversely proportional to distance. In addition, it is interested to note that the amount of electric field strength and magnetic field strength emitted from the power transmission lines increases as the voltage level increases. This implies that as the voltage level of the transmission lines increase, so shall its negative effect, if any, on public health increases. This finding is in agreement with the guidelines values stated in [27], which were presented in Table 1 and Table 2.

To further establish the accuracy of the measured data for this study and its graphical analysis, the obtained graphical results from the study were equally compared with graphs from a similar study presented in [33]. The result of the comparative analysis conducted similarly shows that the obtained graphical results in this study conform perfectly to the graphical results presented in [33]. The difference between the study presented in [33] and the study presented in this paper is that while the reference study, [33], investigated the ELF-EMFs emitted from both televisions screen and personal computer' screen or monitor, this study investigated the ELF-EMFs emitted from high power voltage transmission lines. However, the resemblance nature of the graphical results from the two studies indicates that the methodology employed in this study scientifically relevant while the measured data obtained at the same time are experimentally reliable.

\subsection{Health risk potential of verification of ELF-EMFs}

Furthermore, in predicting the health risks potential of the measured electric field strength, the calculated magnetic field strength and the measured flux density emitted from the four different voltage levels of the transmission levels considered, the obtained measured electric field strength, the calculated magnetic field strength and the measured flux density were compared with guidelines in [27] presented in Table 1 and Table 2 for both occupational and general public respectively. The result of the comparative analysis presented in Table 4 shows that the measured emitted electric field

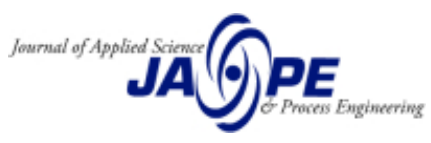


strength, the calculated magnetic field strength and the measured flux density for this study is relatively low compare to the limiting tolerable values in [27]. For instance, for the occupational exposure, the highest measured electric field strength, the calculated magnetic field strength and the measured flux density are about $18.97 \%, 0.69 \%$ and $0.31 \%$ respectively of ICNIP guideline in [27].

Table 4. Comparative health risk potential probability of the measured ELF-EMFs variables with standard guidelines

\begin{tabular}{|c|c|c|c|}
\hline & ccupational Gu & delines Specific & \\
\hline Frequency, $f=$ & $0 \mathrm{~Hz}$ & & \\
\hline Electric field str & igth, E, $(\mathrm{kV} / \mathrm{m})$ : & $00 / f=10.00$ & $\left.V m^{-1}\right)$ \\
\hline Magnetic field & ength, $\mathrm{H},(\mathrm{A} / \mathrm{m})$ : & $8.0 \times 10^{2}=800$ & $0\left(A m^{-1}\right)$ \\
\hline Magnetic flux d & sity, $\mathrm{B},(\mathrm{T}): 25$ & $f=0.50(T)$ & \\
\hline Voltage Level & $\begin{array}{l}\text { Measured, } \mathbf{E}, \\
(\mathrm{kV} / \mathrm{m})\end{array}$ & $\begin{array}{c}\text { Measured, } H, \\
(\mathrm{~A} / \mathbf{m})\end{array}$ & Measured, B, (T) \\
\hline 33 & 0.321 & 0.072 & 0.00000009 \\
\hline 132 & 0.32 & 0.123 & 0.00155 \\
\hline $132 / 330$ & 1.897 & 4.233 & 0.00000532 \\
\hline 330 & 0.0016 & 5.530 & 0.00000702 \\
\hline & eneral Public G & idelines Specific & tion \\
\hline Frequency, $f=$ & $0 \mathrm{~Hz}$ & & \\
\hline Electric field str & gth, E, $(\mathrm{kV} / \mathrm{m})$ : & $50 / f=5.00$ & $\left.m^{-1}\right)$ \\
\hline Magnetic fields & ength, $\mathrm{H},(\mathrm{A} / \mathrm{m})$ : & $1.6 \times 10^{2}=160$ & $\left(A m^{-1}\right)$ \\
\hline Magnetic flux d & sity , B, (T): 25 & $f=0.50(T)$ & \\
\hline Voltage Level & $\begin{array}{c}\text { Measured, } E, \\
(\mathbf{k V} / \mathbf{m})\end{array}$ & $\begin{array}{l}\text { Measured, } H, \\
(\mathrm{~A} / \mathrm{m})\end{array}$ & Measured, B, (T) \\
\hline 33 & 0.321 & 0.072 & 0.00000009 \\
\hline 132 & 0.32 & 0.123 & 0.00155 \\
\hline $132 / 330$ & 1.897 & 4.233 & 0.00000532 \\
\hline 330 & 0.0016 & 5.530 & 0.00000702 \\
\hline
\end{tabular}

Similarly, for the general public exposure, the highest measured electric field strength, the calculated magnetic field strength and the measured flux density are about $37.94 \%, 3.46 \%$ and $0.31 \%$ respectively of guidelines in [27]. This comparative result shows clearly that emitted radiation from ELF-EMFs irrespective of distance has no possible health risks potential as the measured emitted fields' variables are lower than $40 \%$ limited tolerance values. This finding is in agreement with the finding reported in [34] that there is no association between distance to power transmission lines and the risk of childhood leukaemia. Similarly, the relatively low value of the measured electric field of this study compared with the permissible guidelines in [27] buttresses the result of the study reported 
in [22] that electric field in the vicinity of high voltage transmission lines does not responsible for cancer risk in adults. Furthermore, the finding of this study has further confirmed the finding of [17], which reported that both electric and magnetic fields radiated by power transmission lines pose no hazardous health effect on both the occupancy closer to power transmission lines and the general public. This result equally agrees with the finding in [35] that there is no consistent relationship between ELF-EMFs and some reported symptoms. It is, therefore, appropriate to conclude scientifically that electric field strength, magnetic field strength and magnetic flux density from high voltage power transmission lines cannot cause any adverse health effect on workers and the general public.

\section{Conclusion}

The study presents in this paper provides detailed information on measurements of RMS values of ELF-EMFs radiated from HVPTLs. The frequency of operation of the Nigerian power system used is $50 \mathrm{~Hz}$. The measured electric field strength, magnetic field strength and the magnetic flux density were compared with the corresponding limiting tolerable values of each variable at $50 \mathrm{~Hz}$ frequency to predict the potentially hazardous health effect of the fields on people. The result of the comparative result shows that for the occupational exposure, the highest measured electric field strength, the magnetic field strength and the measured flux density are about $18.97 \%, 0.69 \%$ and $0.31 \%$ respectively of ICNIP tolerable values. This comparative result thus, shows that emitted radiation from ELF-EMFs emitted from HVPTLs irrespective of distance has no health risks potential. Furthermore, the obtained result equally shows that the strength of the emitted ELF-EMFs from HVPTLs is inversely proportional to distance. Since the emitted ELF-EMFs from HVPTLs vanish away completely at a $60 \mathrm{~m}$ radius from the transmission lines, it is justified to state that $60 \mathrm{~m}$ from HVPTLs is an experimental possible shortest distance residential building and people can be from HVPTLs to mitigate the exposure level of people to EMFs radiations from HVPTLs.

\section{References}

[1] Ogbogu, O.N., \& Amadi, I.C. (2019). Review on enhancement of electric power transmission using underground cabling, International Journal for Research in Applied Sciences \& Engineering Technology, 7(12), 519-523. ISSN: 2321-9653

[2] Information Sheet Colorado (2014). Overhead Vs Underground information about burying high-voltage transmission lines, Excel Energy, pp. 1-2. Online [Available]: https://www.xcelenergy.com/staticfiles/xe/Corporate/Corporate\%20PDFs/OverheadVsUnderground_FactS heet.pdf. Accessed on December 10, 2020.

[3] Li, X., \& Lin, Y. (2019). Do high-voltage power transmission lines affect forest landscape and vegetation growth: Evidence from a case for Southeastern of China, Forest, 10(2). doi:10.3390/f10020162.

[4] Modenese, A., \& Gobba, F. (2021). Occupational exposure to electromagnetic fields and health surveillance according to the European Directive 2013/EU, International Journal of Environmental Research and Public Health, 18, 1-12. doi:10:33390/ijerph18041730.

[5] Hosseinabadi, M.B., Khanjani, N., Ebrahimi, M.H., Mousavi, S.H., \& Nazarkhani, F. (2020). Investigating the effects of exposure to extremely low frequency electromagnetic fields on job burnout syndrome and the severity of depression; the role of oxidative stress, Journal of Occupational Health, 62(1), 1-8. doi:10.1002/1348-9585.12136.

[6] Garcia, R.M., Novas, N., Alcayde, A., El Khaled, D., Fernandez-Ros, M., \& Gasquez, A. (2020) Progress in the knowledge, application and influence of extremely low frequency signals, Applied Sciences, 10(10), 1-31. doi: 10.3390/app10103494.

[7] Zradzinski, P., Karpowicz, J., Gryz, K., Morzynski, L., Mlynski, R., Swidzinski, A., Godziszewski, K., \& Ramos, V. (2020). Modelling the influence of electromagnetic field on the user of a wearable IoT device 
used in a WSN for monitoring and reducing hazards in the work environment, Sensors, 20(24), 1-15. doi: 10.3390/s20247131.

[8] Wu, S., Di, G. \& Li, Z (2017). Does static electric field from ultra-high voltage direct-current transmission lines affect male reproductive capacity? Evidence from a laboratory study on male mice, Environmental Science and Pollution Research, 24(22), 18025-18034. dio:10.1007/s11356-017-9229-5.

[9] Tong, Z., Dong, Z. \& Ashton, T. (2016). Analysis of electric field influence on buildings under highvoltage transmission lines. IET Science, Measurement \& Technology, 10(4), 253-258. doi 10.1049/ietsmt.2015.0097

[10] Porsius, J.T., Claassen, L., Woudenberg, F., Smid, T. \& Timmermans, D.R. (2016). Nocebo responses to high-voltage power lines: Evidence from a prospective field study, Science of the Total Environment, 543(A), 432-438. https://doi.org/10.1016/j.scitotenv.2015.11.038

[11] Chen Y.J., Chindarkar, N. \& Xiao, Y. (2019). Effect of reliable electricity on health facilities, health information, and child and maternal health services utilization: evidence from rural Gujarat, India, Journal of Health, Population and Nutrition, 38(7). https://doi.org/10.1186/s41043-019-0164-6.

[12] World Health Organization (2014). Access to modern energy services for health facilities in resourceconstrained settings: a review of status, significance, challenges and measurement. Available [Online]: https://apps.who.int/iris/bitstream/handle/10665/156847/9789241507646_eng.pdf?sequence=1\&isAllowed $=\mathrm{y}$. Retrieved November 16, 2020.

[13] Aklin, M, Cheng, C-Y., Urpelainen, J., Ganesan K. \& Jain, A., (2016). Factors affecting household satisfaction with electricity supply in rural India. Nature Energy, 1(11). https://doi.org/10.1038/nenergy.2016.170. https://doi.org/10.1038/nenergy.2016.170

[14] Walle, D., Ravallion, M., Mendiratta, V. \& Koolwal, G. (2017). Long-term gains from electrification in rural India, World Bank Economic Review, 31(2), 385-411 https://doi.org/10.1093/wber/lhv057

[15] Lipscomb, M., Mobarak, A.M. \& Barham, T. (2013). Development effects of electrification: evidence from the topographic placement of hydropower plants in Brazil, American Economic Journal: Applied Economics, 5(2), 200-231 DOI: 10.1257/app.5.2.200

[16] Huang, J., Tang, T., Hu, G., Zheng, J., Wang, Y., Su,.J. Zou, Y. \& Peng, X. (2013). Associated between exposure to Electromagnetic fields from high voltage transmission lines and neurobehavioral function in children, PLOS ONE, 8(7), 1-10. https://doi.org/10.1371/journal.pone.0067284

[17] Nwoke, J.E., Onimisi, M.Y. Jonah, S.A. \& Tafida, R.A. (2017). Measurement and analysis of health effects due to exposure to non-ionizing radiation from high tension cables around Kaduna metropolis, North West, Nigeria, America Journal of Condensed Matter Physics, 7(3), 72-80. DOI: 10.5923/j.ajcmp.20170703.03

[18] Sohrabi, M-R., Tarjoman, T., Abadi, A. \& Yavari, P. (2010). Living near overhead high transmission power lines as a risk factor for childhood acute Lymphoblastic Leukemia: a case-control study, Asian Pacific Journal of Cancer Prevention, 11(2), 423-427 ISSN 15137368

[19] Amoon, A.R., Crespi, C.M., Ahlbom, A., Bhatnagar, M., Bray, I., Bunch, K., Clavel, J., Feychting, M., Hemon, D., Johansen, C., Kreis, C., Malagoli, C., Marquant, F., Pedersen, C., Raaschou-Nielsen, O., Roosli, M., Spycher, B.D., Sudan, M., Swanso, J., Tittarelli, A., Tuck, D.M., Tynes, T., Vergara, X., Vinceti, M., Wunsch-Filho, V. and Kheifets, L. (2018). Proximity to overhead power lines and childhood leukemia: an international pooled analysis, British Journal of Cancer, 119,364-373. ISSN 1532-1827

[20] Draper, G., Vincent, T., Kroll, M. E. \& Swanson, J. (2005). Childhood cancer in relation to distance from high voltage power lines in England and Wales: a case-control Study, British Medical Journal, 330(7503), doi: 10.1136/bmj.330.7503.1290

[21] Elliott, P., Shaddick, G., Douglass, M., de Hoogh, K., Briggs, D.J. \& Toledano, M.B. (2013). Adult cancers near high-voltage overhead power lines, Epidemiology, 24(2), 184-190. doi: 10.1097/EDE.0b013e31827e95b9

[22] Toledano, M.B., Shaddick., G., de Hoogh, K., Fecht, D., Sterrantino, A.F., Matthews, J., Wright, M., Gulliver, J. \& Elliott, P. (2020). Electric field and air ion exposures near high voltage overhead power lines 
and adult cancers: a case control study across England and Wales, International Journal of Epidemiology, 49, i57-i66. doi:10.1093/ije/dyz275.

[23] Ibitoye, F.I. \& Adenikinju, A. (2006). Future demand for electricity in Nigeria, Applied Energy, 84(5), 492504. doi: 10.1016/j.apenergy.2006.09.011.

[24] Reisz, J.A., Bansal, N., Qian, J., Zhao, W. and Furdui, C.M. (2014). Effects of ionizing radiation on biological molecules - mechanisms of damage and emerging methods of detection, Antioxidants \& Redox Signaling, 21(2), 260-292. 292. doi:10.1089/ars.2013.5489.

[25] Sohabi, M-R., Tarjoman, Abadi, A. \& Yavari, P. (2010). Living near overhead high voltage transmission power lines as a risk factor for childhood acute Lymphoblastic Leukemia: a case-control study, Asian Pacific Journal of Cancer Prevention, 11, 423-427. ISSN 1613-7368

[26] Singh, B.K., Sharma, R.S., Ajumeera, R. \& Mathur, A.K. (2008, November). Electromagnetic Fields in Environment and Its Health Hazards, In Proceedings of IEEE International Conference on Recent Advance in Microwave Theory and Applications, Jaipur, India, 558-560. doi: 10.1109/AMTA.2008.4763040

[27] ICNIRP Guidelines (2010). ICNIRP guidelines for limiting exposure to time-varying electric and magnetic fields $\quad(1 \mathrm{~Hz} \quad-\quad 100 \mathrm{kHz})$, Health Physics, 99(6), 818-836. Online: https://www.icnirp.org/cms/upload/publications/ICNIRPLFgdl.pdf

[28] Sinik, V., Despotovic, Z. \& Radovanovic, L. (2013). Influence of non-ionizing radiation on the environment, In Proceedings of 2013 International Science Conference Reporting for Sustainability,465469

[29] Korpinen, L., Kuisti, H., Paakkonen, R., Vanhala, P. \& Elovaara, J. (2011). Occupational exposure to electric and magnetic fields while at switching and transforming stations of $110 \mathrm{kV}$, Annals Occupational Hygiene, 55(5), 526-536. https://doi.org/10.1093/annhyg/mer013

[30] European Parliament and Council (2004). Directive 2004/40/EC of the European Parliament and of the Council on the minimum health and safety requirements regarding the exposure of workers to the risks arising from physical agents (electromagnetic fields) entered into force in the European Union, Official Journal of European Union, 184, 1-9. Online [Available]: https://eurlex.europa.eu/LexUriServ/LexUriServ.do?uri=OJ:L:2004:184:0001:0009:EN:PDF. Accessed on December 29,2020

[31] Ondo State Digest (2009). Digest of demographic and vital statistics of Ondo State, 1-57. Available [Online]:

https://www.google.com/search?q=Ondo + State + Digest $\% 2 C+2009 \&$ oq $=$ Ondo + State + Digest $\% 2 \mathrm{C}+2009 \& \mathrm{a}$ $\mathrm{qs}=$ chrome..69i57.2042j0j15\&sourceid $=$ chrome\&ie=UTF-8. Access January 2, 2021

[32] Electricity Supply Board (1999). Electric and magnetic fields in the environment, pp. $1-23$. Available [Online]: https://www.esb.ie/docs/default-source/default-document-library/keeping-safe/esb-electricmagnetic-fields-in-environment.pdf?sfvrsn=2. Access January 2, 2021

[33] Abdallah, A.S., Abdel-Sattar, S. \& Abdel-Salam, M (2000, March). Human body exposure to electric and magnetic fields radiated from TVs and PCs, In Proceedings of 7th International Middle-East Power Systems Conference, Cairo, 511-515.

[34] Padersen, C., Baruner, E.V., Rod, N.H., Albieri, V., Andersen, C.E., Ulbak, K., Hertel, O., Johansen, C., Schuz, J. \& Raaschou-Nielsen, O. (2014). Distance to high-voltage power lines and risk of childhood leukemia - an analysis of confounding by and interaction with other potential risk factors, PLOS ONE, 9(9), 1-7. https://doi.org/10.1371/journal.pone.0107096

[35] Ahlbom, A., Bridges, J., de Seze, R., Hilert, L., Juutilainen, J., Mattsson, M-O., \& Bromen, K. (2008), Possible effects of electromagnetic fields (EMF) on human health-Opinion of the Scientific Committee on Emerging and Newly Identified Health Risks (SCENIHR), Toxicology, 246(2-3), 248-250. doi:10.1016/j.tox.2008.02.004 